\title{
Dar sentido al patrimonio local: ideas de los estudiantes portugueses y españoles sobre historia
}

\author{
Making Sense of Local Heritage: Portuguese and Spanish Students' Ideas about History \\ Helena Pinto*, Ana Isabel Ponce Gea*
}

\section{Resumen}

La importancia de incluir el patrimonio en la educación viene siendo señalada desde hace décadas por diferentes organismos internacionales. Su inclusión en el proceso de enseñanzaaprendizaje encuentra relaciones con el plano social (la creación de identidades) y con el cognitivo (la construcción de narrativas). En este trabajo planteamos como objetivo comparar las concepciones patrimoniales de 92 estudiantes españoles y portugueses. Para ello, y en el marco de un diseño fenomenológico, aplicamos un instrumento de recogida de información en tres fases, cuyos resultados se han categorizado en torno a dos dimensiones: perspectiva patrimonial y tipología patrimonial. El análisis ha puesto de manifiesto unas tendencias comunes a ambos países, con concepciones tradicionales del patrimonio en cuanto a tipología y perspectiva. La imagen fija del pasado que de los resultados puede inferirse contrasta con las necesidades de este siglo XXI, donde los cambios metodológicos resultan imprescindibles.

Palabras clave: Educación secundaria. Patrimonio. Concepciones. Enseñanza de la historia.

\begin{abstract}
International organizations have pointed out the importance of including heritage in education for decades. Its inclusion in the teaching-learning process finds relationships with the social sphere (the construction of identities) and with the cognitive sphere (the writing of narratives). In this paper we proposed as an objective to compare the heritage conceptions between 92 Spanish and Portuguese students. With this purpose, we developed a research with a phenomenological design, using an only instrument applied in three different stages. The information has been categorized in two dimensions: heritage perspective and heritage typology. The analysis shows common trends to both countries, around traditional conceptions of heritage in terms of typology and perspective. The fixed image of the past, which can be inferred from the results, contrasts with the needs of this 21 st century, where methodological changes are essential.
\end{abstract}

Key words: Secondary Education. Heritage. Conceptions. Teaching of history.

\footnotetext{
* CITCEM, Universidade do Porto • ORCID 0000-0002-7691-9115 • Autora de correspondencia: Helena Pinto (mhelenapinto@gmail.com).

** Universidad de Alicante • ORCID 0000-0003-0432-2595.
}

Pinto, H. y Ponce, A. I. (2020). Dar sentido al patrimonio local: ideas de los estudiantes portugueses y españoles sobre historia. CLIO. History and History teaching, 46, 148-162. https://doi.org/10.26754/ojs clio/clio.2020465328. Recibido: 20/3/2020. Aceptado: 18/9/2020. 


\section{Introducción}

Comenzaremos el texto con una reflexión en torno al patrimonio local, de la mano del Comité de Ministros del Consejo de Europa:

Considering that one of the aims of education is to train young people to have respect for diverse cultures, citizenship, and democracy; (...)

Bearing in mind that cultural heritage is comprised of cultural contributions and interactions from many sources and periods; (...)

Asserting that educational activities in the heritage field are an ideal way of giving meaning to the future by providing a better understanding of the past,

Recommends that the governments of member states adopt appropriate legislative, regulatory, administrative, financial and other measures to initiate and develop heritage education activities and to promote heritage awareness among the young (Consejo de Europa, 1998, p. 31).

Esta recomendación del Consejo de Europa (Recomendación 98 (5)) se formuló en 1998, más de dos décadas atrás. En ella ya se apuntaba que la educación patrimonial tenía que formar parte de todos los niveles y tipos de enseñanza, añadiendo además que debía hacerse a través de las diferentes asignaturas escolares. Los métodos activos y la variedad en los modos de comunicación eran otras de las cuestiones tratadas por el Comité.

Desde entonces, las investigaciones y propuestas en torno a lo patrimonial han sido frecuentes. Desde que la idea de educación patrimonial comienza a desarrollarse (Fontal, 2003), se han ido adoptando diferentes enfoques en todas las direcciones y contextos, con muy interesantes resultados (Trabajo y Cuenca, 2017, por poner algún ejemplo de los últimos, entre otros muchos representativos). Cada uno de ellos ha aportado valiosas perspectivas en aras a comprender el concepto de patrimonio de un modo holístico que resulta necesario.

Muchos de estos estudios han ahondado en la perspectiva y la tipología patrimonial (por ejemplo, Santacana y Martínez, 2013), analizando con frecuencia la relación entre el patrimonio y la construcción de una identidad. No obstante, si analizamos los objetivos de la educación en el siglo XXI, entendiendo el patrimonio como parte de la enseñanza y el aprendizaje de la historia, algunos aspectos resultan de interés. 
En primer lugar, concebir el patrimonio como identidad puede no resultar suficiente si en esa concepción no existe una reflexión sobre su utilidad. En otras palabras, el patrimonio no puede limitarse a ser solo una representación -incluso, siendo históricasino que debe ser parte de los esquemas del pasado que cada alumno posea, lo que implica participar en la construcción del argumento histórico y su significado.

En segundo lugar, las perpectivas patrimoniales y la tipología patrimonial no son aspectos independientes ni descontextualizados. De hecho, la forma en la que los estudiantes conectan los tipos de patrimonio con las perspectivas patrimoniales nos da información de sus concepciones sobre la historia.

En tercer lugar, si en el plano social el patrimonio puede asociarse con la identidad, en el plano cognitivo está vinculado a las narrativas que en torno a él se conforman. Así, podemos encontrarnos con elementos patrimoniales no argumentados históricamente (lo que categorizaremos después como patrimonio-objeto); elementos en torno a los cuales se crea una narrativa única, frecuentemente patriótica y forjadora de identidades colectivas duras (patrimonio-conmemoración); y elementos entendidos como fuentes históricas y, por lo tanto, que permiten e implican, en el plano cognitivo, la presencia de narrativas múltiples (patrimonio-recurso). Podemos encontrar posicionamientos en torno a lo anterior en autores que van desde Nietzsche a otros tantos más actuales (Gónzalez-Monfort, 2007; Martín y Cuenca, 2015).

En cuarto y último lugar, el patrimonio es el producto de una determinada cultura. Entender las concepciones patrimoniales requiere considerar los conceptos más amplios de cultura y cultura histórica (Rüsen, 2007; 2009).

Considerando todo lo anterior, el patrimonio local parece una buena opción tanto para el trabajo en las aulas como para la investigación en torno a concepciones patrimoniales. Por un lado, la escala de lo local resulta muy relevante a la hora de crear identidades y, en cualquier caso, el componente emocional está asegurado. Por otro lado, los elementos patrimoniales locales están a disposición del alumnado, que puede, a través de ellos, ver las huellas de la historia en todo aquello que observa cada día.

Partiendo del propósito de un análisis que permita la comprensión del patrimonio en el marco de la enseñanza de la historia, y de la idea de que las diferencias culturales 
pueden conllevar también diferencias a la hora de entender el patrimonio, nos planteamos en este estudio una comparación entre las concepciones patrimoniales de los estudiantes portugueses y españoles de secundaria.

\section{Objetivos de la investigación}

De acuerdo con el problema inicial y al encuadre teórico, concretamos los objetivos de la investigación en la Tabla 1.

\begin{tabular}{ll}
\hline Objetivo general & Objetivos específicos \\
\hline $\begin{array}{l}\text { 1. Comparar las concepciones } \\
\text { patrimoniales de los estudiantes }\end{array}$ & $\begin{array}{l}\text { 1.1. Describir la perspectiva usada por los estudiantes } \\
\text { en relación con el patrimonio. }\end{array}$ \\
\cline { 2 - 2 } & $\begin{array}{l}\text { 1.2. Identificar el tipo de patrimonio más frecuentemente } \\
\text { escogido por los estudiantes. }\end{array}$ \\
\cline { 2 - 2 } & $\begin{array}{l}\text { 1.3. Comprender las relaciones entre las perspectivas } \\
\text { patrimoniales y el tipo de patrimonio seleccionado. }\end{array}$ \\
\hline
\end{tabular}

Tabla 1. Objetivos de la investigación

\section{Metodología}

\section{Diseño}

En aras a dar respuesta a los objetivos de investigación delimitados, planteamos un estudio de tipo descriptivo, bajo un enfoque interpretativo de metodología cualitativa. Concretamente, adoptamos un diseño fenomenológico (Martínez, Castellanos y Chacón, 2014), con el fin de conocer una realidad compartida en los dos contextos de los que proceden los participantes (España y Portugal).

\section{Participantes}

En la investigación han participado un total de 92 estudiantes, de entre 13 y 15 años de edad, que se encuentran cursando la escolaridad obligatoria. Entre ellos, 52 estudiantes son españoles (56.52\%) y 40 son portugueses $(43.48 \%)$. 
Instrumento y procedimiento de recogida de información

Para la recogida de información, hemos utilizado un único instrumento, implementado, sin embargo, en tres fases y apoyado en categorías validadas en un grupo de discusión previo.

Para sintetizar la implementación del instrumento (conformado por una tarea de lápiz y papel y la realización de una fotografía), podemos utilizar el proceso 1-1-1 seguido con los propios participantes:

$\checkmark 1$ idea. El investigador introduce la idea que vertebra la recogida de información. Para ello, pronuncia la palabra "patrimonio" sin más explicación al respecto. Esta fase puede entenderse como parte de las instrucciones para la aplicación del instrumento.

$\checkmark 1$ palabra. Ofrecemos a los participantes una lista de palabras (en su mayoría, adjetivos) correspondientes a las categorías de análisis. Pensando sobre la idea -es decir, el patrimonio-, los participantes han de seleccionar, entre las palabras ofrecidas, la primera que relacionen con la idea. Solo pueden seleccionar una palabra.

$\checkmark 1$ imagen. Pedimos a los participantes que realicen una fotografía combinando la idea de patrimonio con la palabra escogida en la fase anterior. Esta fotografía ha de hacerse en el entorno local.

\section{Análisis de la información}

A la hora de analizar la información, se han utilizado categorías de naturaleza inductivo-deductiva, estructuradas en dos dimensiones ("Perspectiva patrimonial" y "Tipología patrimonial") y de acuerdo con el procedimiento representado en la figura 1. 


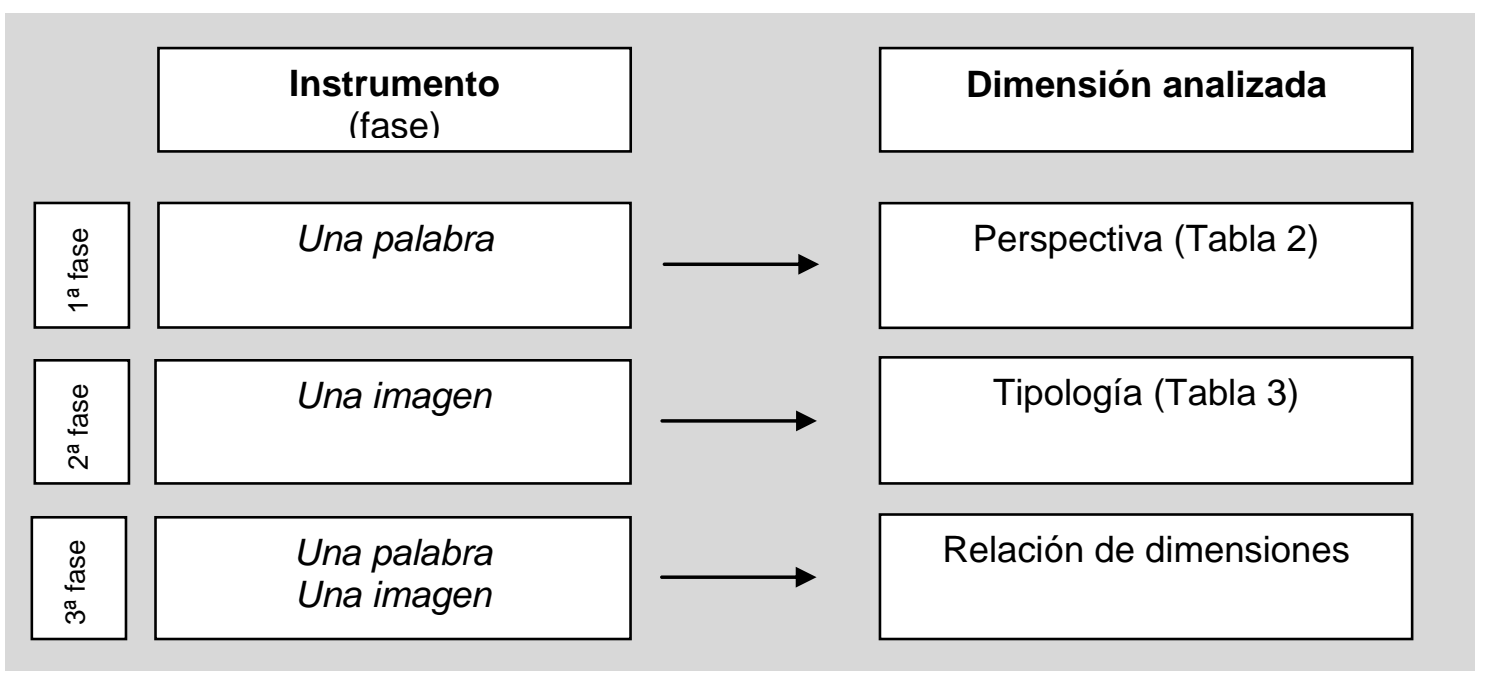

Figura 1. Proceso de análisis (elaboración propia).

Por un lado, para la dimensión "Perspectiva patrimonial", se han considerado para el análisis tres categorías (Tabla 2), de tipo deductivo, basadas en las aportaciones de González Morfort (2007) y Martín y Cuenca (2015), entre otros. La agrupación se ha realizado en relación con el papel del patrimonio en el contexto de enseñanzaaprendizaje: ilustrativo, conmemorativo, o como fuente histórica, principalmente.

\begin{tabular}{lll}
\hline & \multicolumn{2}{c}{ Perspectiva patrimonial } \\
\hline Patrimonio-objeto & Patrimonio-conmemoración & Patrimonio-recurso \\
& & \\
\hline Antiguo & Emotivo & Informativo \\
Bello & Nuestro & Rentable \\
Singular & Simbólico & Útil \\
Extraño & Propio & Válido \\
& & \\
\hline
\end{tabular}

Tabla 2. Categorías de la dimensión "Perspectiva patrimonial"

Por otro lado, las categorías de la dimensión "Tipología patrimonial" han sido definidas a través de un proceso de categorización deductivo-inductivo, correspondiendo, esencialmente a las aportaciones de Martín y Cuenca (2015). 


\begin{tabular}{lllll}
\hline \multicolumn{4}{c}{ Tipología del patrimonio } \\
\hline $\begin{array}{l}\text { Natural-histórico- } \\
\text { artístico }\end{array}$ & Etnológico & $\begin{array}{l}\text { Científico- } \\
\text { tecnológico }\end{array}$ & Holístico & Otros \\
\hline $\begin{array}{l}\text { Elementos } \\
\text { naturales }\end{array}$ & $\begin{array}{l}\text { Costumbres } \\
\text { Festividades }\end{array}$ & $\begin{array}{l}\text { Actividades } \\
\text { industriales }\end{array}$ & $\begin{array}{l}\text { Patrimonio } \\
\text { holístico }\end{array}$ & Otros \\
$\begin{array}{l}\text { Elementos } \\
\text { históricos }\end{array}$ & Leyendas & & & \\
$\begin{array}{l}\text { Elementos } \\
\text { artísticos }\end{array}$ & Música & & \\
& & & & \\
\hline
\end{tabular}

Tabla 3. Categorías de la dimensión "Tipología patrimonial"

\section{Resultados y discusión}

Expondremos los resultados tomando como referencia los objetivos específicos considerados para el estudio.

Perspectiva de los participantes sobre el patrimonio

Los resultados relativos al primer objetivo específico quedan incluidos en la Tabla 4. En relación con la perspectiva patrimonial, la categoría "Patrimonio-conmemoración" representa un porcentaje del $63.04 \%$ de las respuestas de los participantes, seguida de la categoría "Patrimonio-objeto" (34.78\%). Solo dos respuestas corresponden a la categoría "Patrimonio-recurso". 


\begin{tabular}{|c|c|c|c|c|c|}
\hline \multicolumn{2}{|c|}{ Patrimonio-objeto } & \multicolumn{2}{|c|}{$\begin{array}{l}\text { Patrimonio- } \\
\text { conmemoración }\end{array}$} & \multicolumn{2}{|c|}{ Patrimonio-recurso } \\
\hline$E S$ & $P T$ & $E S$ & $P T$ & $E S$ & $P T$ \\
\hline Antiguo & Antiguo & Emotivo & Emotivo & Informativo & Informativo \\
\hline Bello & Bello & Nuestro & Nuestro & Rentable & Rentable \\
\hline (3) & (2) & (9) & (6) & (0) & (0) \\
\hline Escaso & Escaso & Simbólico & Simbólico & Útil & Útil \\
\hline (1) & $(0)$ & (19) & (18) & (0) & $(1)$ \\
\hline Extraño & Extraño & Propio & Propio & Válido & Válido \\
\hline (2) & $(0)$ & $(1)$ & $(1)$ & $(0)$ & $(0)$ \\
\hline 20 & 12 & 31 & 27 & 1 & 1 \\
\hline \multicolumn{6}{|c|}{ Porcentajes internos a cada país } \\
\hline 38.46 & 30 & 59.62 & 67.5 & 1.92 & 2.5 \\
\hline \multicolumn{6}{|c|}{ Porcentajes totales de cada categoría } \\
\hline 34.78 & & 63.04 & & 2.18 & \\
\hline
\end{tabular}

Tabla 4. Resultados en relación con la "Perspectiva patrimonial"

Aunque hay diferencias entre las respuestas dadas por los participantes de ambos países -la distancia entre "Patrimonio-conmemoración" y "Patrimonio-objeto" es mayor en el caso de Portugal-, las tendencias son similares.

La categoría "Patrimonio-conmemoración" incluye 58 de las 92 respuestas, siendo el adjetivo más utilizado "simbólico", seguido de "nuestro". Este resultado es común a España y Portugal, por lo que los estudiantes parecen prestar atención, para la definición del patrimonio, a dos aspectos principales: los elementos simbólicos relativos a la visión simbólica del pasado (Pinto, 2016) - y la idea de propiedad patrimonio es algo que es nuestro y no de cualquier otro, algo que nos hace únicos-. No hemos de obviar que, en el plano social, esta categoría es la más directamente asociada con la identidad, entendiendo la identidad aquí como una identidad tradicional, patriótica y dura (Rachik, 2006).

En el caso de la categoría "Patrimonio-objeto", la edad del elemento patrimonial resulta determinante. Sin embargo, esta visión temporal no permite a priori una argumentación histórica, sino que representa una definición tan vacía, desde el punto de vista histórico, como una argumentación en torno a la belleza o la extrañeza del elemento. 
Este tipo de razonamiento es más frecuente en España que en Portugal, lo que puede dar indicios de que el patrimonio se relacione más a menudo con cuestiones sentimientos y de identidad en el segundo de los países, evitando con ello el argumento más superficial.

La concepción del patrimonio como recurso, lo que incluye su utilización como fuente histórica, no prevalece entre los estudiantes; siendo los casos categorizados una mera excepción en la tendencia, en línea con otras investigaciones realizadas a este respecto (Seixas y Clark, 2004). Este hecho prueba, una vez más, que la historia no es concebida como una construcción por la mayoría de los estudiantes, sino una narrativa cerrada que no es susceptible de dudas en relación con su formulación. Historia y pasado se tratan como sinónimos, alejando a la displina histórica de su rol real de creadora de conocimiento (Lowenthal, 1998; Jenkins, 2009).

\section{Tipología patrimonial más frecuentemente utilizada}

En relación con la tipología patrimonial (Tabla 5), el "Patrimonio natural-históricoartístico" representa un $82.61 \%$ de las respuestas, llegando incluso al $90 \%$ en el caso de Portugal. Los estudiantes españoles seleccionan más a menudo elementos vinculados a costumbres, festividades, leyendas o música, encontrando un único ejemplo para los participantes portugueses.

Entre todas las respuestas, solo podemos categorizar un elemento como "Patrimonio holístico", resultado de un collage de imágenes que incluyen diferentes tipos de patrimonio.

\begin{tabular}{|c|c|c|c|c|c|c|c|c|c|}
\hline \multicolumn{2}{|c|}{ Natural-histórico-artístico } & \multicolumn{2}{|c|}{ Etnológico } & \multicolumn{2}{|r|}{$\begin{array}{l}\text { Científico- } \\
\text { tecnológico }\end{array}$} & \multicolumn{2}{|c|}{ Holístico } & \multicolumn{2}{|c|}{ Otros } \\
\hline$E S$ & $P T$ & $E S$ & $P T$ & $E S$ & $P T$ & $E S$ & $P T$ & $E S$ & $P T$ \\
\hline $\begin{array}{l}\text { Natural } \\
(2) \\
\text { Histórico } \\
(29) \\
\text { Artístico } \\
\text { (9) }\end{array}$ & $\begin{array}{l}\text { Natural } \\
(0) \\
\text { Histórico } \\
(19) \\
\text { Artístico } \\
(17)\end{array}$ & $\begin{array}{l}\text { Costumbres (2) } \\
\text { Festividades } \\
(2) \\
\text { Leyendas (1) } \\
\text { Música (1) }\end{array}$ & $\begin{array}{c}\text { Costumbres } \\
\text { (1) }\end{array}$ & (0) & $\begin{array}{l}\text { Actividadesin } \\
\text { dustriales } \\
\text { (2) }\end{array}$ & (1) & (0) & (2) & (1) \\
\hline 40 & 36 & 9 & 1 & 0 & 2 & 1 & 0 & 2 & 1 \\
\hline \multicolumn{10}{|c|}{ Porcentajes internos a cada país } \\
\hline 76.92 & 90 & 17.31 & 2.5 & 0 & 5 & 1.92 & & 3.85 & 2.5 \\
\hline \multicolumn{10}{|c|}{ Porcentajes totales de cada categoría } \\
\hline & & 10.8 & & & 2.17 & 1. & & & \\
\hline
\end{tabular}

Tabla 5. Resultados en relación con la "Tipología patrimonial" 
De acuerdo con los resultados, los elementos patrimoniales más frecuentes son los históricos, dentro de la categoría también más frecuente de "Patrimonio naturalhistórico-artístico". Otros tipos de patrimonio, como el científico-tecnológico, son realmente infrecuentemente. En la mencionada categoría tan solo encontramos dos ejemplos en el caso de Portugal.

En síntesis, ocho de cada diez estudiantes portan una idea tradicional del patrimonio en relación con su tipología.

Relaciones entre la perspectiva y tipología patrimonial

La tipología y la perspectiva patrimonial encuentran relación, tal y como podemos observar en la Tabla 6.

La combinación entre "Patrimonio natural-histórico-artístico" y "Patrimonioconmemoración" representa el $52.17 \%$ del total de las respuestas, seguido del par "Patrimonio natural-histórico-artístico" y "Patrimonio-objeto".

Si atendiendo a las investigaciones realizadas en esta línea, y a las tendencias en la didáctica del patrimonio y de la historia en general, consideramos la concepción ideal en la combinación de "Patrimonio holístico" y "Patrimonio-recurso", parece que nos encontramos muy lejos de esta aspiración, sin ningún ejemplo entre las respuestas dadas por los participantes.

El resto de las combinaciones presentan porcentajes realmente bajos, entre los que podría destacarse la combinación de "Patrimonio etnológico" y "Patrimonioconmemoración" con un $7.61 \%$. 


\begin{tabular}{|c|c|c|c|c|c|}
\hline & $\begin{array}{l}\text { Natural- } \\
\text { histórico- } \\
\text { artístico }\end{array}$ & Etnológico & $\begin{array}{l}\text { Científico- } \\
\text { Tecnológico }\end{array}$ & Holístico & Otros \\
\hline & \multicolumn{5}{|c|}{ España/Portugal } \\
\hline \multirow{5}{*}{ 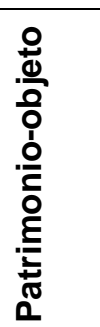 } & $15 / 11$ & $3 / 0$ & $0 / 1$ & $0 / 0$ & $2 / 0$ \\
\hline & \multicolumn{5}{|c|}{ Porcentajes internos a cada país } \\
\hline & $28.85 / 27.5$ & $5.77 / 0$ & $0 / 2.5$ & $0 / 0$ & $3.85 / 0$ \\
\hline & \multicolumn{5}{|c|}{ Porcentajes totales de cada categoría } \\
\hline & 28.26 & 3.26 & 1.09 & 0 & 2.17 \\
\hline \multirow{5}{*}{ 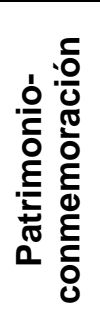 } & $24 / 24$ & $6 / 1$ & $0 / 1$ & $1 / 0$ & $0 / 1$ \\
\hline & \multicolumn{5}{|c|}{ Porcentajes internos a cada país } \\
\hline & $46.15 / 60$ & $11.54 / 2.5$ & $0 / 2.5$ & $1.92 / 0$ & $0 / 2.5$ \\
\hline & \multicolumn{5}{|c|}{ Porcentajes totales de cada categoría } \\
\hline & 52.17 & 7.61 & 1.09 & 1.09 & 1.09 \\
\hline \multirow{5}{*}{ 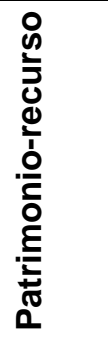 } & $1 / 1$ & $0 / 0$ & $0 / 0$ & $0 / 0$ & $0 / 0$ \\
\hline & \multicolumn{5}{|c|}{ Porcentajes internos a cada país } \\
\hline & $1.92 / 2.5$ & $0 / 0$ & $0 / 0$ & $0 / 0$ & $0 / 0$ \\
\hline & \multicolumn{5}{|c|}{ Porcentajes totales de cada categoría } \\
\hline & 2.18 & 0 & 0 & 0 & 0 \\
\hline
\end{tabular}

Tabla 6. Resultados de la combinación de "Tipología patrimonial" y "Perspectiva patrimonial"

Tras este análisis, consideramos interesante prestar atención a algunos de los elementos seleccionados por los estudiantes, incluyendo en la figura 2 los elementos más frecuentemente seleccionados y en la figura 3 aquellos que resultan excepcionales. 


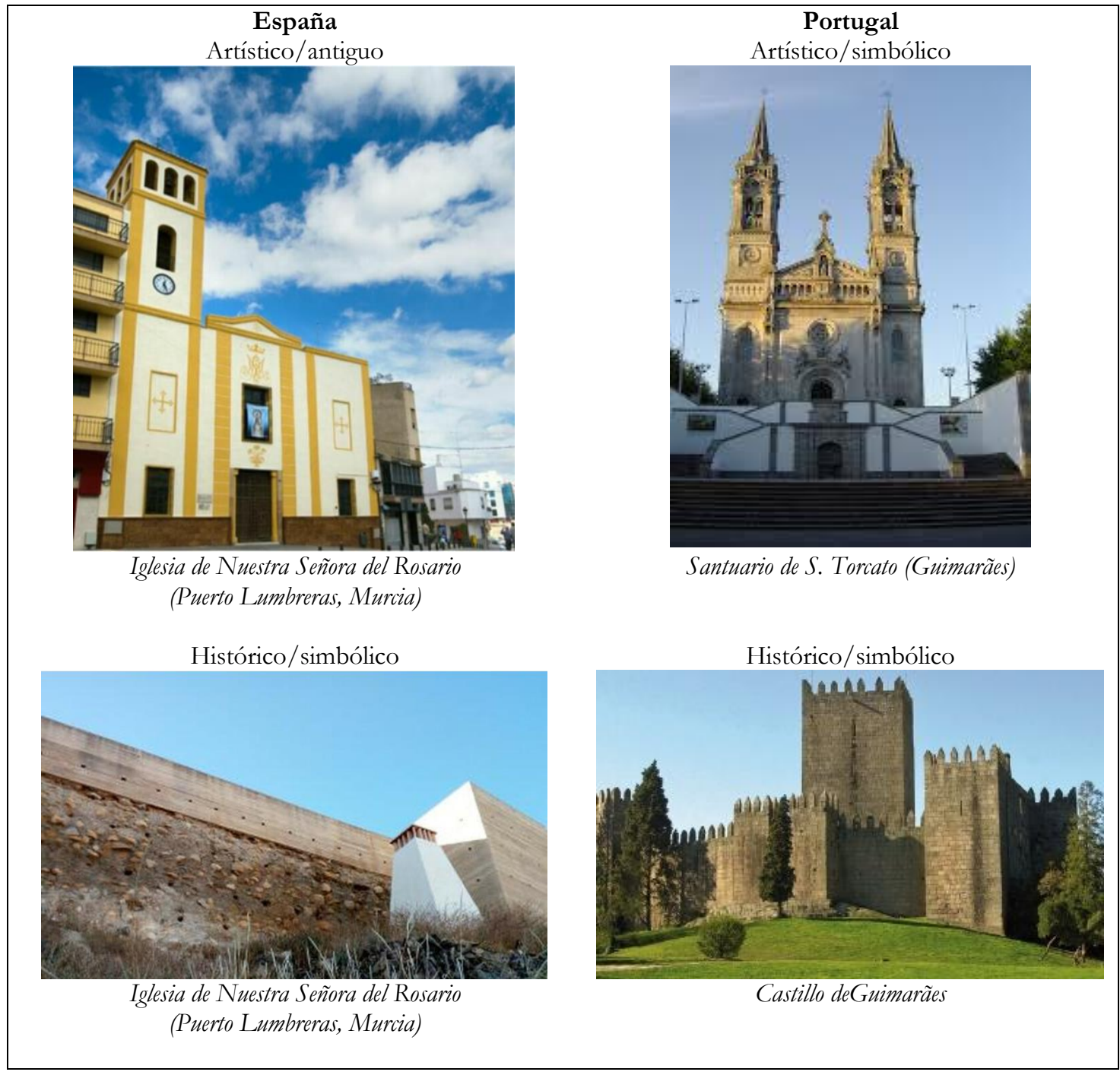

Figura 2. Elementos patrimoniales frecuentes

Si bien es cierto que la diferencia entre estas figuras resulta de más utilidad para el tipo de patrimonio que para la perspectiva en torno a él, hemos hecho refencia a esta cuestión aquí por ser analizados los elementos bajo las dos categorías. Ciertamente, podemos observar cómo los elementos más frecuentes son muy similares, estando la idea de lo histórico-artístico asociada a iglesias y castillos y, en todo caso, alejadas de la perspectiva del patrimonio como recurso. Existe, sin embargo, más diversidad en aquellas elecciones que calificamos como excepcionales. Como se ve en la Figura 3, recorren la música, las costumbres o la industria, estando indudablemente condicionadas por el patrimonio local existente en cada uno de los municipios escogidos. 
Emotivo/música (1)

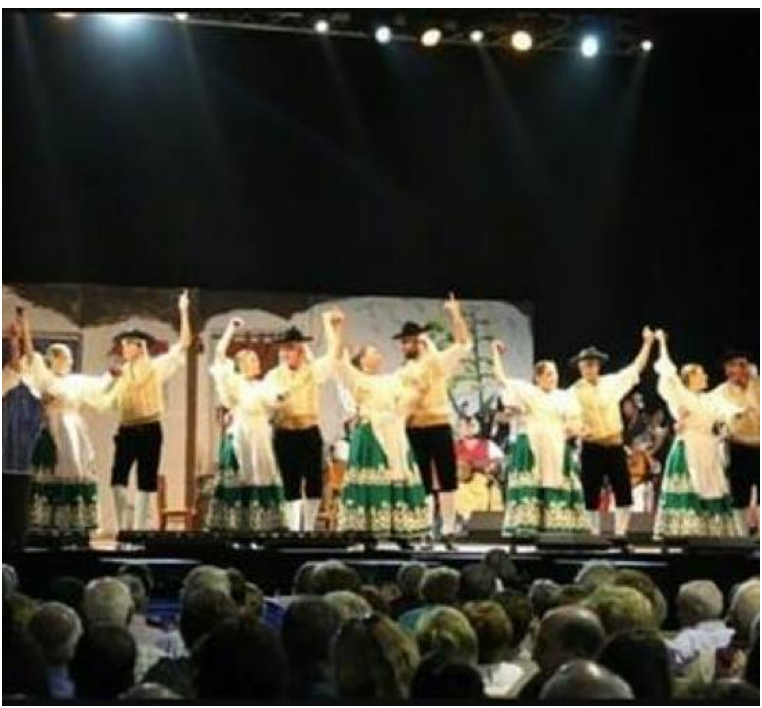

Nuestro/holístico (3)
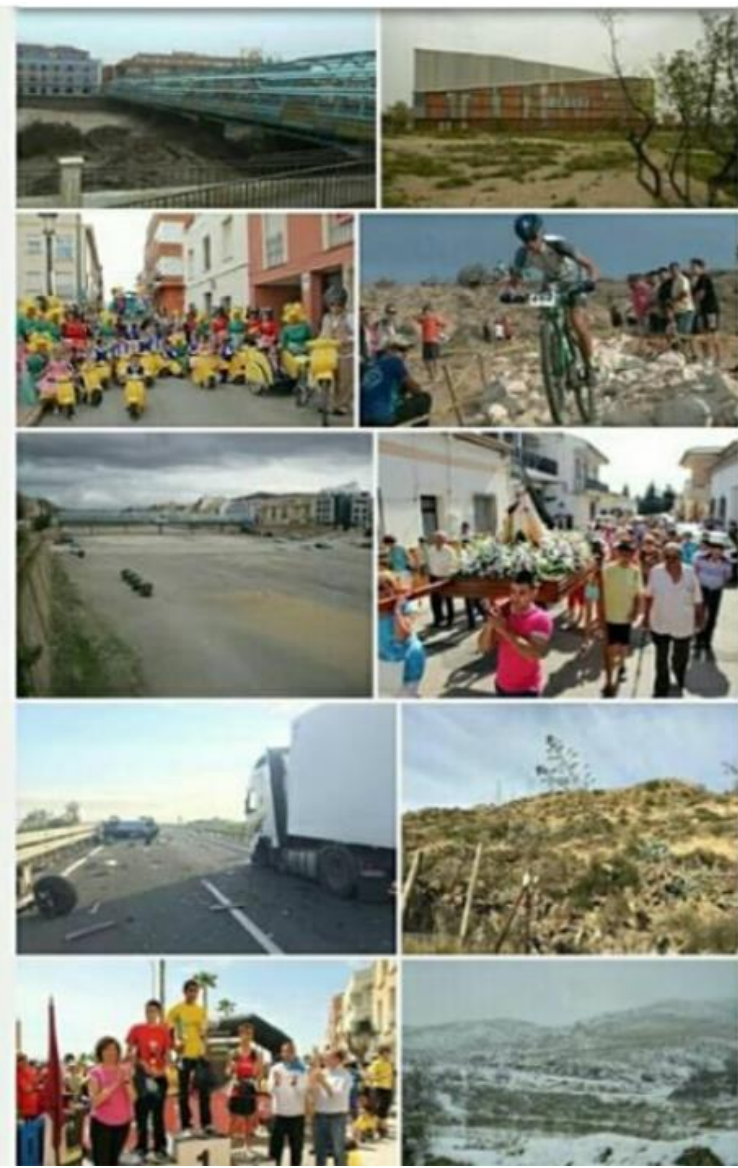

Simbólico/costumbres (2)
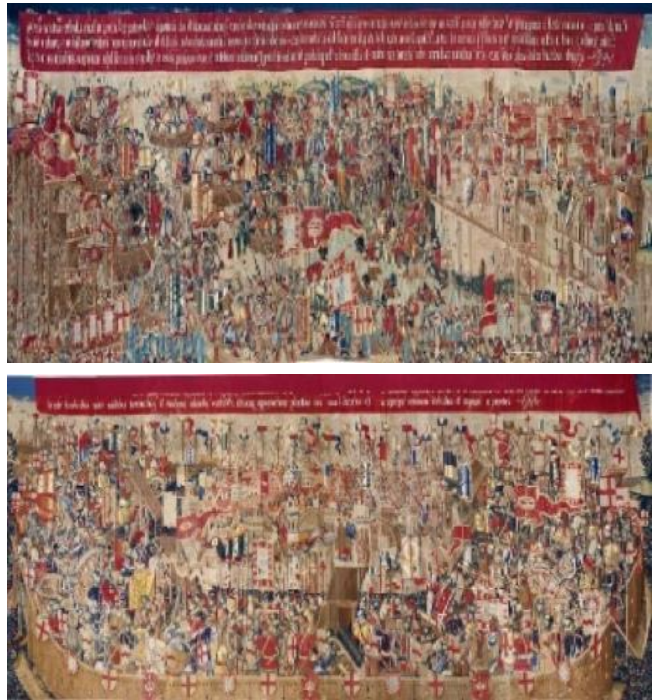

Nuestro/actividades industriales (4)

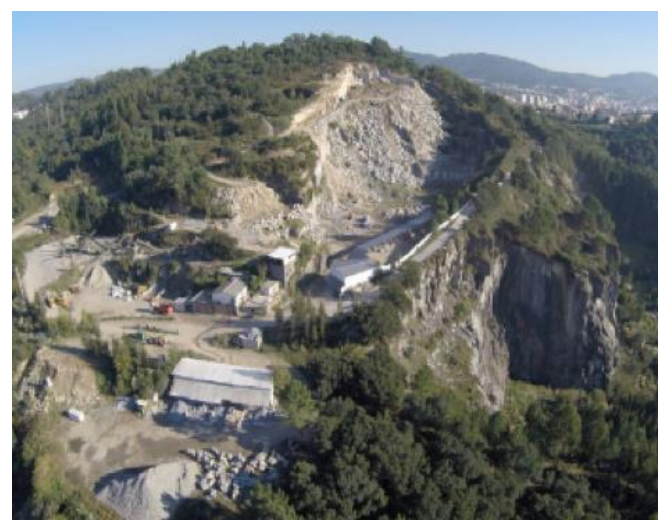

(1) Grupo folklórico Virgen del Rosario (Puerto Lumbreras, Murcia)

(2) Tapices de Pastrana (copia) sobre Asilah y la conquista de Tánger (Paço dos Duques de Bragança, Guimarães)

(3) Elementos patrimoniales diversos (Puerto Lumbreras, Murcia)

(4) Extracción de piedra de granito en Gonça (Guimarães) 


\section{Conclusiones}

Los enfoques de la historia escolar y de la educación patrimonial en España y Portugal, de acuerdo con ambos currículos, no son idénticos. Sin embargo, los resultados muestran muchas coincidencias entre las concepciones de los estudiantes de ambos países sobre qué es el patrimonio (tipología) y cuál su utilidad (perspectiva).

Salvo algunas excepciones, del análisis se desprende un uso tradicional del patrimonio $y$, por lo tanto, una concepción tradicional de la historia. Mientras los cambios en las sociedades de este ya no tan nuevo siglo son cada vez más evidentes y los asuntos controvertidos van ganando en importancia, el pasado (y los resultados de este) sigue viéndose como una imagen fija, como un símbolo con un sentido identitario, asociado a la idea más originaria de la historia escolar como forjadora de las naciones.

El siglo XXI presenta muchos retos y, en el ámbito educativo, aprender a aprender y aprender a vivir juntos resultan fundamentales.

Para esta formación de ciudadanos críticos y tolerantes, la historia escolar juega, sin duda, un papel y el patrimonio puede convertirse en un facilitador de primer orden. Sin embargo, su enfoque debe ser reformulado en aras de a convertirlo en una fuente histórica a partir de la cual crear discursos históricos críticos y creativos.

Para lo anterior se necesita la suma de la legislación, los cambios metodológicos, la formación docente y mucho empeño.

Solo así conseguiremos eso que el Consejo de Europa lleva diciendo ya... más de 20 años.

\section{Agradecimientos}

A los alumnos de los centros educativos implicados. A la Fundación Séneca, Agencia de Ciencia y Tecnología de la Región de Murcia, por el contrato predoctoral (19811/FPl/15) y sus sucesivas ayudas a estancias en centros de investigación externos, de los que disfrutó la segunda autora. AI CITCEM, centro de investigación al que pertenecen las autoras [trabalho cofinanciado pelo Fundo Europeu de 
Desenvolvimento Regional (FEDER) através do COMPETE 2020 -Programa Operacional Competitividade e Internacionalização (POCI) e por fundos nacionais através da FCT, no ámbito do projeto POCI-01-0145-FEDER-007460].

\section{Referencias}

Consejo de Europa (1998) Recommendation No. $R$ (98) 5 of the Committee of Ministers of to member states concerning heritage education. Adopted by the Committee of Ministers on 17 March 1998 at the 623rd meeting of the Ministers' Deputies. https://rm.coe.int/16804f1ca1

Fontal, O. (2003) La educación patrimonial: teoría y práctica en el aula, el museo e internet. Trea.

González-Monfort, N. (2007). L'ús didàctic i el valor educatiu del patrimoni cultural [tesis doctoral]. Repositorio de la Universidad Autónoma de Barcelona. https://ddd.uab.cat/record/36572

Jenkins, K. (2009) Repensar la historia. Siglo XXI.

Lowenthal, D. (1998) El pasado es un país extraño. Akal.

Martín, M., y Cuenca, J.M. (2015). Educomunicación del patrimonio. Educatio Siglo XXI, 33(1), 33-54.

Martínez, R., Castellanos, M.A. y Chacón, J.C. (2014). Métodos de investigación en Psicología. EOS Universitaria.

Pinto, H. (2016). Educação histórica e patrimonial: Conceções de alunos e professores sobre o passado em espaços do presente. CITCEM.

Rachik, H. (2006). Identidad dura e identidad blanda. Revista CIDOB d'Afers Internacionals, 73$74,9-20$.

Rüsen, J. (2007). How to make sense of the past - salient issues of Metahistory. TD: The Journal for Transdisciplinary Research in Southern Africa, 3(1), 169-221.

Rüsen, J. (2009). ¿Qué es la cultura histórica?: Reflexiones sobre una nueva manera de abordar la historia. Cultura histórica. [Versión castellana inédita del texto original alemán en K. Füssmann, H. T. Grütter y J. Rüsen (Eds.) (1994), Historische Faszination. Geschichtskulturheute (pp. 3-26). Böhlau http://www.culturahistorica.es/ruesen/ cultura historica.pdf

Santacana, J. y Martínez, T. (2013). Patrimonio, identidad y educación: una reflexión teórica desde la historia. EducatioSiglo XXI, 31(1), 47-60.

Seixas, P. y Clark, P. (2004). Murals as monuments: students' ideas about depictions of civilization in British Columbia. American Journal of Education, 110(2), 146-171.

Trabajo, M. y Cuenca, J. Ma․ (2017). La educación patrimonial para la adquisición de competencias emocionales y territoriales del alumnado de enseñanza secundaria. Pulso. Revista de Educación, 40, 159-174. 